\title{
USING PORTFOLIO THEORY TO PREDICT THE IMPACT OF REDUCTION IN PRODUCT WIDTH ON SALES
}

\author{
Tomasz Brzęczek \\ Faculty of Engineering Management, Poznan University of Technology, \\ Strzelecka Str. 11, 60-965 Poznan, Poland \\ E-mail: tomasz.brzeczek@put.poznan.pl
}

Received 09 January 2015; accepted 12 November 2015

\begin{abstract}
Modern portfolio theory was applied to research product portfolio diversification. Prior research studies claimed a positive relationship between the number and variety of products and sales smoothing. However, they have also argued the limitations of classical portfolio analysis, especially owing to the assumption of independence of portfolio shares and the static nature of the approach. To address this limitation we extend the model to fit the trend and seasonality of sales, and to cover their correlations. The model aims to predict the impact of product width reduction on sales and their volatility. We consider the reduction of a product category in portfolio. The model covers the impact of product category sales on portfolio sales but also on other product category sales. Finally, we verify the model using a wholesaler company's data and compare results. Hence, we recommend the model for the prediction of changes in sales and their volatility due to product category reduction. The model covers the portfolio dynamic approach to product width under the assumption of price taking, unlike in product assortment and variety planning models.
\end{abstract}

Keywords: modern portfolio theory, product width, product category reduction, sales mean and variance, sales smoothing, seasonality smoothing.

JEL Classification: C51, L25, M21, M31.

\section{Introduction}

There is a significant impact of product portfolio complexity on sales and on operating costs as well (Jacobs, Swink 2011). The complexity requires a holistic understanding of multidimensional product relationships at multiple levels of analysis including product, portfolio, and supply chain (Jacobs 2013). We consider the product portfolio analysis that has arisen in the management literature in the context of strategic management and marketing strategy, and has gained wide acceptance among managers of diversified companies (Day 1977; Cooper et al. 1999; Mallin, Finkle 2011). It was initially used mainly to analyse the effect of product innovations on a firm's competitive position. Rosenbloom (1980) argued that strategic market planning implies the use of fairly sophisticated planning methods as portfolio analysis for business defining in terms of offered product category conglomeration. This problem in the wholesales and retailing 
context is of our interest in this paper. A time-constrained consumer that prefers onestop and multi-store shopping puts pressure on retailers to broaden their assortment with different product categories and even non-core product categories (Ailawadi, Keller 2004). Marketing research studies give general recommendations for cross-category assortment extensions. By introducing a series of closely related but increasingly distant extensions, very different product categories should be introduced (Meyvis, Januszewski 2004; Mantrala et al. 2009). Inman et al. (2004) note that certain types of product categories have associations with specific channels, e.g., a supermarket with food. However, we can observe supermarkets selling a very wide scope of products, including household items or even gasoline. Ma et al. (2011) find significant impact of gasoline prices on grocery shopping behaviour also toward product width. Hence, to explain product extension implications for sales, we model an opposite operation of reduction in existing product width and its impact on sales and their volatility. The model and estimation of the impact of category reduction on total sales level and volatility have received little attention so far (Wan et al. 2014). This is especially the case when assortment reduction concerns competitive product relationships (Kök et al. 2009: 130). We are not interested directly in assortment planning on the product level, otherwise known as product assortment or assortment depth (Hart, Rafiq 2006), which is the process conducted by the retailer to determine the number and types of products in a line (Rajaram 2001), or product variety planning, which is about determining the number of style and colour combinations within a specific product group, corresponding broadly to the number of "models", otherwise known as stock keeping units (SKUs) (Vaagen, Wallace 2008). However, we find these works to be useful for us, because they introduced the portfolio theory approach in assortment selection and their conclusions are also interesting for our theme of product width, which means the selection of product categories into a portfolio.

In this paper we address a question: how to model total sales change due to a reduction or expansion of a product category if competitive product relationships are taken into account. We extend the portfolio theory model for resolving this question. Please note that observed assortment strategies often add only one non-core product. It is usually a homogeneous product that has no variants. Good examples for such homogenous products are: petrol, kinds of fruits or vegetables. Another example could be a standardised product, for example an accessory item or spare part dedicated for some product's brand and model. Although offering of a single product in some category is rare, it also can be analysed in our model. We incorporate the correlation between product category sales to model their competitive relationships and their impact on sales level and volatility. We applied our method at a large wholesaler specializing in agricultural equipment and spare parts, but also offering a broad range of household and garden items, and non-core product categories (i.e. toys, pet accessories and food).

The rest of this paper is organized as follows. In Section 1 we highlight existing work that provides us with applications of the portfolio theory to production and sales management. In Section 2 we propose our method, which allows us to study the structure of product category sales and the driving trend, seasonality and competitive forces behind it. Empirical data analysis and prediction of portfolio sales and volatility changes owing to product category reduction are given in Section 3. We end with concluding remarks. 


\section{Literature review}

Modern portfolio theory was developed by Harry Markowitz (1959) in a book entitled Portfolio Selection. The model trades-off efficiently risk for return in determining the optimal allocation of an investor's overall investment portfolio across investment alternatives (Sharpe 1970). The objective is to minimise the portfolio risk for any fixed expected rate of return. The risk in the model is defined by the variance of the random payoffs from the investments. Diversification of the risk is possible owing to a lack of perfect positive correlation of return rates of securities, which takes place if any correlation coefficient has a level below one. The smaller the coefficient, the more risk can be diversified, and the entire risk can be diversified if the correlation is perfectly negative. Since the introduction of the model many studies have been carried out to develop it so it would fit other variety and risk management problems. Strategic management uses the BCG or Ansoff matrix to model diversification of products' life cycles and cash flows in order to form appropriate market strategy and make decisions about new product development (Day 1977; Cooper et al. 1999; Gabrielsson, P., Gabrielsson, M. 2004; Jugend, da Silva 2014). The segmentation of customers and its strategic effect is also studied thanks to portfolio theory (Johnson, Selnes 2004). Modern portfolio theory and the mean-variance analysis have been applied also in logistics and retailing literature (Kök et al. 2009; Mantrala et al. 2009). Logistics literature focuses on risk of a supply chain and production costs. Cadeaux (1992) found that the volatility of the industrial product line content arguably contributes to the uncertainty that retailers face. Lee et al. (1997) have proved that demand variability amplifies as one moves up a supply chain, which is known as the bullwhip effect. The best solution is a postponed ordering strategy that allows for a reduced retailer, and further reduced supply chain, variability, but also means that producers have to bear more risk of costs. Hence, producers introduce: component commonality, available excess production capacity, dual-sourcing and the option to run overtime in order to achive production costs smoothing and flexibility (Swaminathan, Tayur 1998). The main resource for retailers is shelf space. Goto (2008) uses the portfolio model to optimise shelf space. Van Mieghem (2003) gives a literature review on strategic capacity management under uncertainty.

Our research has a lot in common with the research on product portfolio complexity in operation management literature (Jacobs, Swink 2011). Jacobs and Swink (2011) define product portfolio complexity as a design state manifested by the multiplicity, diversity and interrelatedness of products within the portfolio. They also provide a comprehensive review of the research on theoretical perspectives describing complexity's effects on operational costs and sales performance. Some research studies focus on determining optimal resource allocations for a portfolio of new products (Loch, Kavadias 2002; McNally et al. 2009) or finding the right balance between radical and incremental innovation (Chao, Kavadias 2008). Dekimpe et al. (2011) consider multi format portfolio and expanding of portfolio width as the main challenges in retailing. Hence, we focus on applications of modern portfolio theory to modelling of product width decisions impact on sales that is also the issue of interest of retailing and marketing. The applications concern different levels and dimensions of assortment. Hart 
and Rafiq (2006) give a comprehensive review of literature on assortment dimensions terminology in retailing and on product mix terminology in marketing. Hart and Rafiq (2006: 342) define "width" as "the number of departments or extent of different product classifications offered by the retailer". Following them and product mix terminology we define "product width", that is the main subject of our interest, as the number of different product categories or product lines offered by a store. Kumar and Banga (2007: 8) interchangeably use the term "breadth of assortments". Others synonymously use terms "breadth of assortment across the store" and "variety of the store assortment" (Kahn 1999: 289; Kök et al. 2009: 130).-

The stream of research, which we focus on, proved the benefits of sales smoothing owing to product or retail format conglomeration (Gerchak, He 2003; Hassanzadeh et al. 2014). The modern portfolio theory model's direct application has been used by Brown (2010) to manage profitability of the retail format portfolio. "A retail format is the retailer's type of retail mix (nature of merchandise and services offered, pricing policy, advertising and promotion program, approach to store design and visual merchandising and typical location)" (Levy, Weitz 1998: 161). Brown (2010) describes the limitations of direct applications and in particular the assumption of independence of formats' sales and returns. He argues that a number of portfolio components and their amount and share not only affect portfolio results, but also are dependent from each other. Our model covers the dependence of product category sales, unlike the financial investment portfolio model, in which allocations across investment alternatives are independent, although their returns are dependent. So the model provides a mean-variance method to analyse sales hedging due to product width. This is of particular importance as Jacobs and Swink (2011: 686) argue that "aggregate sales volatility mediates the effects of diversity on a) fixed assets utilization and b) operational performance". Ton and Raman (2010) search for a cause and find that as a company's product variety increases, so too do errors in demand forecasting and information systems.

Our model distinguishes between sales compensation that results from seasonality, and from trend and residual sales variability as Gorman and Brannon (2000) recommend. Akkerman and van Donk (2009: 2) find that "variability in the product mix causes short term imbalance" and "seasonal demands and new product introductions can result in products which have demand that is positively or negatively correlated with the demand for other products". Product category competitive relationships in sales are estimated in the literature with different methods. Bandyopadhyay (2009) model them using BVAR and seasonal dummy variables. Mehta (2007) also models cross-category competition, although from the point of view of the consumer that makes a basket choice. He uses a logit model and faces the problem how to aggregate data and estimates. We compare the results of our portfolio model with the findings of Sloot et al. (2006), who studied a similar problem of assortment reduction in product category using single equation econometric modelling. Cadeaux and Yee (2013) develop a structural equation model of category sales volatility and heterogeneity impact on category assortments and performance. However, our portfolio model of sales works with any method estimates for product categories. Thus, parameters from different methods of estimation can be used simultaneously for existing product categories and for new product category expectations. 
Product assortment planning is the research stream which focuses at simulation and optimisation of product relations effects on sales and costs performance. Its objective is usually profit maximisation subject to resource allocation in production (Rajaram 2001). It considers product level of assortment and some research studies consider the impact of a product variety on sales risk. Trappey et al. (1993) give a comprehensive review of the theme. Many studies address risk issues in the single-item newsboy problem; hence they are not directly applicable for studying product variety impact on risk (Atkinson 1979; Agrawal, Seshadri 2000). Multi-item newsboy type models, for the so-called "newsstand problem", can be viewed as assortment planning models for a given variety (Haksever, Moussourakis 2005). Vaagen and Wallace (2008: 435) argue, "Despite the significance of the mean-variance theory in financial portfolio building, it has not been directly used for industrial product variety problems". In a study by Vaagen and Wallace (2008), we found the usage of sales correlation between stock keeping units in two uncertain states of the world that simulates a bi-modal distribution of demand. In addition, Lau, H.-S. and Lau, H.-L. (1997) recognize that demand seldom fits normal or exponential distributions, and propose a demand distribution modelling procedure combining empirical data with a subjective understanding of the environment. Our extension of the portfolio model is such a technique. Especially covers for dynamic impact of category reduction on other categories and total sales as managers suggest. According to Bata et al. (2011: 4) "Once an expansion or reduction opportunity has been identified for a category, the incrementality of that category must be assessed relative to all other categories in order to quantify the expected overall increase or decrease in sales".

\section{Model formulation}

In this chapter the extension of portfolio analysis is proposed in order to model and predict the impact of category cut on sales and their volatility. The model is feasible for the assumptions that:

1. Model sales equal turnover from quantities of supply and demand in dynamic equilibrium concerning the macro and market environment (stationary or nonstationary in time) and additive seasonality. The case company has a forecasting system that predicts a trend and seasonality of sales.

2. Residual sales represent a deviation from equilibrium turnover owing to the competitive relationships of product categories covering all factors, for example a relative price exogenous change, product shortage (stock-out), fashion and preferences change and changes in customers' income. Positive correlation represents complementary product categories and negative correlation represents substitutable product categories.

3. The trend, seasonality and residual sales are independent from each other for each product category.

The classic portfolio model can be found in Markowitz (1959) or in Sharpe (1970). Notation in our model (1-5) is as follows:

1. Set $I$ - number of product categories in the portfolio, for which indexes $i, j, k=$ $1,2, \ldots I$ are used. 


\section{Variables:}

$y_{\mathrm{i}}$ - seasonally adjusted sales for category $i$,

$y_{\mathrm{p}}$ - seasonally unadjusted portfolio sales,

3. Parameters:

$b_{\text {it }}-$ structural change of sale for category $i$ expected in period $t$,

$c_{\text {itl }}$ - additive seasonal effect for category $i$ expected in period $t$ and season $l(l=$ $1, \ldots L)$,

$d_{\mathrm{it}}$ - standard error of estimation of the coefficient $b$ in period $t$ for category $i$, $s_{\mathrm{i}}$ - standard deviation of residual sale for category $i$,

$\rho_{\mathrm{ik}}-$ correlation coefficient between residual sales of category $i$ and category $k$,

$\rho_{\mathrm{pk}}-$ correlation coefficient between residual sales of category $k$ and the rest of the portfolio.

Appropriate parameters measure trend in the expected sales, seasonal effect and competitive relationships between product categories. The structural change results from trend or non-stationary smoothing of the sale. By residual sale we mean the seasonally adjusted and detrended sale. Hence, the expected change in portfolio sales owing to a full reduction of sale for category $k$ in period $t$ and season $l$ is modelled as follows:

$$
E\left(\Delta y_{p k t l}\right)=-\left(y_{k, t-1}+b_{k, t-1}+c_{k t l}\right)\left(1+\rho_{p k}\right) .
$$

The first bracket covers the full reduction of the product category sale and the last bracket covers the competitive impact of the reduction on portfolio sale that is measured with $\rho_{\mathrm{pk}}$. The competitive effect is estimated for residual sales, because all product categories have their own structural and seasonal effects. However, it affects the whole amount of reduction, because the structural and seasonal effects are cut for the given category and imply a competitive impact on the portfolio. Hence, Equation (1) covers the time and seasonal dynamics of sales but also their implied competitive portfolio effect. To assess the results in the entire seasonal cycle we calculate the competitive effects in lasting $L-1$ seasons:

$$
E\left(\Delta y_{p k m}\right)=\left(-b_{k, t-1}-c_{k m}\right)\left(1+\rho_{p k}\right), \quad m=1, \ldots, L, m \neq l .
$$

Hence the yearly seasonal effects compensate themselves, and the total yearly effect is the following:

$$
E\left(\Delta y_{p k}\right)=\left(-y_{k, t-1}-4 b_{k, t-1}\right)\left(1+\rho_{p k}\right) .
$$

Taking such an approach, we follow up Sloot et al. (2006), who found that there is a short- and long-term competitive impact of an assortment reduction on category sales. The impact of reduction in product width on the volatility of sales is decomposed into structural, seasonal and residual volatility. Structural volatility of sales could be measured with the variance of coefficients $b$, or as we did with their standard estimation errors $d$, and their covariance between product categories. We attribute this systematic volatility to external factors of the economy and market. Hence, we assume that trend estimators for product categories are perfectly positively correlated, i.e. an economy growth state reduces the decreasing sale trend (the actual structural change has 
a higher value than the expected negative $b$ ) and boosts the increasing sale trend (the actual structural change has a higher value than the expected positive $b$ ). Vice versa, an economy slowdown state implies lower actual values than the expected coefficients $b$. Assuming a perfect positive correlation between coefficients $b$ and their independence from seasonal and residual deviations, we measure the impact of the category $k$ reduction on structural variance of sales in the forecasted period $t$ ' as follows:

$$
-t^{\prime 2}\left(d_{k}^{2}+2 \sum_{i \neq k}^{I} d_{i} d_{k}\right) \text {. }
$$

Concerning residual sales, they are correlated between product categories but independent from seasonality and the trend. So the impact of category $k$ reduction on the residual, competitive variance of the portfolio is:

$$
-\left(s_{k}^{2}+2 \sum_{i \neq k}^{I} \rho_{i k} s_{i} s_{k}\right) .
$$

Similarly, we can calculate the impact of category $k$ reduction on seasonal variance of sales:

$$
-\left(\sum_{l=1}^{L} c_{k l}^{2}+2 \sum_{i \neq k}^{I} \sum_{l=1}^{L} c_{i l} c_{k l}\right) / L .
$$

Proof of propositions (3-5) are shown in Appendix. The overall change of sales variance is a total of changes $(3-5)$.

Price is not controlled in our model, so the implications are valid for companies that are price takers. However, the model is also useful for price makers whose price volatility is small. In such a case, the shortage of a product category, known as stock-out, is the result of a category's average price being too low and implies negative residual sales for the category itself and complementary categories, and positive residual sales for substitutable categories. Surplus of the category supply results in higher inventory stocks owing to its too high price, but in terms of inelastic demand it also results in positive residual sales for the category itself and complementary categories, and negative residual sales for substitutable categories.

\section{Model implementation}

We applied the model at a large wholesaler specializing in agricultural equipment and spare parts, but also offering a broad range of household and garden items, and noncore product categories (i.e. toys, pet accessories and food). The analysed company supplied 150 of its own retailers and 1949 total retailers during the years 2005-2011. The company offered over 39000 products, from which 24000 were in everyday offer. We analysed sales in 10 product categories, which were:

1. Power transmission (drive shafts, bearing and housings, fasteners and seal rings, belt drives and pulleys, chain and accessories, geared motors and gearboxes, shaft couplings, lubrication systems and service tools). 
2. Professional clothing, toys and leisure (shoes, boots, gloves, first aid and safety kits, books, puzzles, models, outdoor and winter toys, go-carts and pedal vehicles).

3. Machines and equipment for harvesting and transport (combines, lawn movers).

4. Tractor and vehicle parts (lighting, cab and truck bodies, suspension, brakes, engines and others).

5. Tools and workshop equipment (grinding, abrasives, tools).

6. Machines and equipment for sowing, cultivation and protection (drilling, tillage and sprayer parts).

7. Grass and feeding parts.

8. Foodstuff and equipment for horses and pets.

9. Hydraulics.

10. Wheels and tyres for agricultural machines.

For each product category we estimated an appropriate model of sales with parameters of structural, seasonal and residual volatility. The methods of estimation and estimated parameters are summarised in Table 1. We started with tests of time series autocorrelation and the unit root test of stationarity (ADF, KPSS) in order to choose an appropriate model. The estimation period covers quarterly time series from 2005 till the end of 2011. Winters' smoothing model parameters were optimised. In the case of dynamic parameters, like those in Winters' exponential smoothing, we used the most updated

Table 1. Estimation of product categories' sales models (PLN thousands)

\begin{tabular}{|c|c|c|c|c|c|c|c|c|c|c|}
\hline \multirow{2}{*}{$\begin{array}{c}\text { Tests and } \\
\text { parameters }\end{array}$} & \multicolumn{10}{|c|}{ Product categories: } \\
\hline & 1 & 2 & 3 & 4 & 5 & 6 & 7 & 8 & 9 & 10 \\
\hline $\begin{array}{l}\text { Volatility } \\
\text { test result }\end{array}$ & \multicolumn{3}{|c|}{ Linear Trend } & Stationary & $\begin{array}{l}\text { Linear } \\
\text { trend }\end{array}$ & \multicolumn{5}{|c|}{ Non-stationary } \\
\hline Method & GLS & \multicolumn{2}{|c|}{ OLS } & Average & OLS & \multicolumn{5}{|c|}{ Winters exponential smoothing } \\
\hline $\begin{array}{l}\text { Constant } \\
\text { term }\end{array}$ & -283 & -1 & 1106 & 3612 & 953 & - & - & - & - & - \\
\hline$b_{\text {it }}$ & 130 & 74 & 57 & 0 & 167 & 53 & 0 & -1 & 183 & 4 \\
\hline$d_{\text {it }}$ & 9 & 9 & 8 & 0 & 21 & 5 & 0 & 13 & 65 & 1 \\
\hline Seasonality & \multicolumn{10}{|c|}{ Quarterly additive effects with zero total } \\
\hline$c_{i t l=1}$ & -17 & -199 & -320 & 992 & 213 & 539 & 125 & -98 & 225 & 104 \\
\hline$c_{i t l=2}$ & 424 & -432 & 1149 & 474 & 1753 & -289 & 353 & 47 & -143 & 30 \\
\hline$c_{i t l=3}$ & -43 & -244 & 611 & 157 & 92 & 1413 & -118 & 101 & 4 & 54 \\
\hline$c_{i t l=4}$ & -364 & 875 & -1441 & -1624 & -2057 & -1663 & -359 & -50 & -87 & -189 \\
\hline$R$-squared & 0.84 & 0.85 & 0.93 & 0.82 & 0.83 & 0.85 & 0.52 & 0.78 & 0.91 & 0.63 \\
\hline$s_{i}$ & 441 & 330 & 291 & 472 & 831 & 557 & 340 & 108 & 239 & 149 \\
\hline $\begin{array}{l}\text { Residual } \\
\text { Autocorrel. }\end{array}$ & $\begin{array}{l}\mathrm{AR}(4) \\
-0.53\end{array}$ & $-^{*}$ & $-^{*}$ & $-^{*}$ & $-^{*}$ & $-^{*}$ & $-^{*}$ & $-^{*}$ & $-^{*}$ & $-^{*}$ \\
\hline
\end{tabular}

Note: * autocorrelation of residuals not significant at $10 \%$ level. 
trend coefficients and seasonal effects, from 2011, after mean centring them. The most updated dynamic parameters were chosen because modern portfolio theory is a forwardlooking normative approach that should be applied with forecasted returns. However, we simultaneously used all 24 quarter period estimators for stationary data series or linear trends, because past behaviour is one predictor of future returns and, therefore, using historical data is not inappropriate in implementing portfolio theory (Bodie et al. 2009).

Knowing the parameters, we calculate $y_{i, t-1}$, which represents seasonally adjusted sales for category $i$ in the last quarter of 2011, and from (1-2) we calculate the total sales effects of each category reduction in the quarters of 2012. We put the results in Table 2. For the first quarter of 2012 we estimated the direct effect of reduction, that is $E\left(\Delta y_{p k t}\right)$. Most categories are complementary to the portfolio, because reduction of each of them leads to a higher decrease in portfolio sales than sales of the reduced category. A reduction of category 2 or category 7 decreases portfolio sales by smaller amount than the category sales. So those categories would be substituted to some degree within the portfolio in the first quarter. However, concerning all four quarters, only sales of categories 5 and 7 would be partially substituted. Categories 1, 3, 6 and 8-10 are strongly complementary to portfolio sales on an annual scale, and the remaining categories 2 and 4 are independent.

When calculating risk effects, we cannot only consider residual correlation coefficient $\rho$, but also structural trends in sales and seasonal pattern influence given by the formulas (3-5). The impact of these factors on total sales risk is presented in Table 3.

For each category, the smallest impact on portfolio sales variance has trend volatility; of course, this is in a quarterly period. In the longest horizon, trend variance rises with the square number of forecasted periods, as formula (3) informs. Category 9 has the highest impact on portfolio structural variability, but it also has the highest positive coefficient of the trend - see $b_{i t}$ in Table 1. Categories 4 and 7 have no trend and no variance of the trend. Category 8 has a medium impact on risk and hardly any positive trend, so it has the worst trade-off between trend and volatility.

Seasonal volatility is the main contribution of each category, excluding category 9 , into portfolio variance. Categories 8 and 9 have the smallest seasonal and total volatility. However, category 2 , with high itself seasonality, reduces the total seasonal variance of the portfolio. It drives sales up in the fourth quarter, when other categories face seasonal drops - see row $c_{i t l=4}$ in Table 1 . The main contributors to the high seasonal volatility of portfolio sales are categories 3-6. These categories include agricultural machines and materials especially needed in time during harvest but also tools and workshop equipment. A natural solution in order to decrease those categories seasonal risk would be to offer maintenance services for those machines.

The only category that reduces residual variance of portfolio sales is substitutable category 7, because its reduction would increase residual variance of portfolio by 154684 million squared PLN. The reduction of any of the remaining nine categories would lead to a decrease of residual variance of sales. Among them, categories 1, 3, 5-6 and 8-10 are complementary and categories 2 and 4 are independent. 
Table 2. Estimation of total sales effects of each product category full reduction in portfolio in quarters of 2012 (PLN thousands)

\begin{tabular}{lcccccccccc}
\hline \multirow{2}{*}{ Estimate } & \multicolumn{10}{c}{ Product categories: } \\
\cline { 2 - 11 } & 1 & 2 & 3 & 4 & 5 & 6 & 7 & 8 & 9 & 10 \\
\hline$y_{i, t-1}$ & 3349 & 2070 & 2700 & 3612 & 5630 & 3466 & 2359 & 788 & 2608 & 1028 \\
\hline$\rho_{p i}$ & 0.182 & -0.004 & 0.329 & -0.020 & -0.140 & 0.311 & -0.262 & 0.363 & 0.266 & 0.231 \\
\hline$E\left(\Delta y_{p k t l}\right)$ & -4094 & -1937 & -3239 & -4514 & -5165 & -5325 & -1833 & -929 & -3824 & -1399 \\
\hline$E\left(\Delta y_{p k, m=2}\right)$ & -655 & 357 & -1603 & -465 & -1650 & 304 & -260 & -53 & -57 & -42 \\
\hline$E\left(\Delta y_{p k, m=3}\right)$ & -103 & 169 & -888 & -154 & -222 & -1926 & 87 & -127 & -243 & -72 \\
\hline$E\left(\Delta y_{p k, m=4}\right)$ & 277 & -945 & 1839 & 1592 & 1625 & 2106 & 265 & 79 & -128 & 228 \\
\hline$E\left(\Delta y_{p k}\right)$ & -4575 & -2356 & -3891 & -3541 & -5413 & -4841 & -1741 & -1031 & -4252 & -1284 \\
\hline
\end{tabular}

Table 3. Estimation of total sales volatility effects of each product category full reduction in portfolio in $2012\left(\mathrm{PLN}^{2}\right.$ millions)

\begin{tabular}{ccccc}
\hline $\begin{array}{c}\text { Product } \\
\text { category }\end{array}$ & $\begin{array}{c}\text { Portfolio structural } \\
\text { variance effect }\end{array}$ & $\begin{array}{c}\text { Portfolio seasonal } \\
\text { variance effect }\end{array}$ & $\begin{array}{c}\text { Portfolio residual } \\
\text { variance effect }\end{array}$ & $\begin{array}{c}\text { Portfolio total } \\
\text { variance effect }\end{array}$ \\
\hline 1 & -2383 & -1843990 & -407039 & -2253412 \\
\hline 2 & -2318 & 4437575 & -104602 & 4330655 \\
\hline 3 & -1968 & -6349526 & -341834 & -6693328 \\
\hline 4 & 0 & -6414692 & -197094 & -6611786 \\
\hline 5 & -4891 & -8527336 & -380026 & -8912253 \\
\hline 6 & -1316 & -5868897 & -722970 & -6593183 \\
\hline 7 & 0 & -1749550 & 154684 & -1594867 \\
\hline 8 & -3177 & -270825 & -122897 & -396899 \\
\hline 9 & -9146 & -223530 & -233097 & -465773 \\
\hline 10 & -88 & -830952 & -119863 & -950904 \\
\hline
\end{tabular}

Assessing the total sales and total variance effects of category reduction, we found no product category for which sales would be strongly substituted and risk would be lowered due to its reduction. The strongest substitution $\left(\rho_{p k=7}=-0.26\right)$ was found for category 7 , "Grass and feeding parts", for which about $25 \%$ of sales could be substituted with other categories. This category reduction would result with $8 \%$ reduction in total variance due to accumulation with portfolio seasonality and only $1.6 \%$ drop in total sales. A benchmark for our estimated total variance effects and per cent effects is the non-modelled variance of total sales that equals 21808027 million squared PLN and total sales of 107 million PLN in 2011. One should remember that the total variance effects in Table 3 shouldn't be totalled, because they estimate the impact on portfolio variance for each category in relation to the remaining nine categories. This implies a 
need for effect recalculating for each change of the content of product categories in the portfolio. This also proves a dynamic nature of the proposed model. Additionally our study confirms a strong seasonality of sales and the company should think about a new product category that could be sold to its customers in the fourth quarter, such as repair services for the offered machines. A good example is offered category 2 which residual sales are independent from the portfolio sales but their seasonal sales are negatively correlated and compensate themselves.

\section{Conclusions}

The introduced model is a useful technique for the prediction of the impact of product category reduction on total sales and their volatility. The model addresses the limitations of modern portfolio theory in sales modelling. One investment allocation decision does not affect the results of the other investments, but only total portfolio effect. In our model, any product category reduction affects directly total sales and also indirectly by the effect on sales of other categories. This effect is due to product competition, which we model with the correlation coefficient of residual sales. The model also covers trends' compensation and seasonal compensation. Trends, seasonality and residual effects are assumed to be independent from each other, hence additive seasonality is used. This is the limitation of the study. The model is not accurate for multiplicative seasonality of category sales. Our model also implies the impact of a category reduction on total sales variance but not on the volatility of sales of each product category remaining in the portfolio. Modern portfolio theory should be applied to forecasted expected sales, which we achieve using the last sales level and extrapolating it with trends, seasonality and autoregressive residuals if necessary. Further methodological research should relax model assumptions to cover a broader scope of applications. Substitution mechanisms concerning different areas of decisions: assortment planning, capacity planning, inventory decision, and pricing decision could be modelled, if the assumption of price exogeneity was relaxed (Shin et al. 2015). Further empirical research could also examine the verification of model implications in different branches. It would also be interesting to study the impact of the level of product category homogeneity on portfolio sales and variance.

However, the formulated model fits the company analysed in this study. The analysed company is a large wholesaler and pursues a product-pricing policy based on pricetaking from suppliers. Hence, the main decision is what product category to offer. This decision affects total sales and variance. Total profit is related to sales and the profit margin rate, which is fixed due to competition. Empirical verification revealed the need for the use of various volatility and forecasting models for product category data series to estimate the model parameters. Our recommendations for the case study company are not to reduce any product category. It should extend its offer with additional services for the most seasonal product category or introduce a new product category with a positive seasonal effect in the fourth quarter. 


\section{References}

Agrawal, V.; Seshadri, S. 2000. Impact of uncertainty and risk aversion on price and order quantity in the newsvendor problem, Manufacturing and Service Operations Management 2: 410-423. http://dx.doi.org/10.1287/msom.2.4.410.12339

Ailawadi, K. L.; Keller, K. L. 2004. Understanding retail branding: conceptual insights and research priorities, Journal of Retailing 80(4): 331-342.

http://dx.doi.org/10.1016/j.jretai.2004.10.008

Akkerman, R.; van Donk, D. P. 2009. Product mix variability with correlated demand in twostage food manufacturing with intermediate storage, International Journal of Production Economics 121(2): 313-322. http://dx.doi.org/10.1016/j.ijpe.2006.11.021

Atkinson, A. A. 1979. Incentives, uncertainty, and risk in the newsboy problem, Decision Science 10: 341-357. http://dx.doi.org/10.1111/j.1540-5915.1979.tb00030.x

Bandyopadhyay, S. 2009. A dynamic model of cross-category competition: theory, tests and applications, Journal of Retailing 89(4): 468-479. http://dx.doi.org/10.1016/j.jretai.2009.05.001

Bata, S. A.; Beard, J.; Egri, E.; Morris, D. 2011. Retail revenue management: applying datadriven analytics to the merchandise line of business, Journal of Business and Retail Management Research 5(2): 43-54.

Bodie, Z.; Kane, A.; Marcus, A. J. 2009. Investments. 8th ed. Boston: McGraw-Hill Irwin.

Brown, J. R. 2010. Managing the retail format portfolio: an application of modern portfolio theory, Journal of Retailing and Consumer Services 17(1): 19-28.

http://dx.doi.org/10.1016/j.jretconser.2009.09.001

Cadeaux, J. 1992. Industry product volatility and retailer assortments, Journal of Macromarketing 12(2): 28-37. http://dx.doi.org/10.1177/027614679201200204

Cadeaux, J.; Yee, L. 2013. Performance effect of category assortment and stock allocation decisions for a cash-and-carry wholesaler, International Review of Retail, Distribution \& Consumer Research 23(5): 537-552. http://dx.doi.org/10.1080/09593969.2013.835741

Chao, R. O.; Kavadias, S. 2008. A theoretical framework for managing the new product development portfolio: when and how to use strategic buckets, Management Science 54(5): 907-921. http://dx.doi.org/10.1287/mnsc.1070.0828

Cooper, R. G.; Scott, J. E.; Kleinschmidt, E. J. 1999. New product portfolio management: practices and performance, Journal of Product Innovation Management 16(4): 333-351.

http://dx.doi.org/10.1016/S0737-6782(99)00005-3

Day, G. S. 1977. Diagnosing the product portfolio. How to use scarce cash and managerial resources for maximum long-run gains, Journal of Marketing 41(2): 29-38.

Dekimpe, M. G.; Gielens, K.; Raju, J.; Thomas, J. S. 2011. Strategic assortment decisions in information-intensive and turbulent environments, Journal of Retailing 87(S): S17-S28.

Gabrielsson, P.; Gabrielsson, M. 2004. Globalizing internationals: business portfolio and marketing strategies in the ICT field, International Business Review 13(6): 661-684.

http://dx.doi.org/10.1016/j.ibusrev.2004.10.001

Gerchak, Y.; He, Q.-M. 2003. On the relation between the benefits of risk pooling and the variability of demand, IIE Transactions 35(11): 1027-1035. http://dx.doi.org/10.1080/07408170304399

Gorman, M. F.; Brannon, J. I. 2000. Seasonality and the production-smoothing model, International Journal of Production Economics 65(2): 173-178.

http://dx.doi.org/10.1016/S0925-5273(99)00049-3

Goto, H. 2008. An optimal portfolio of shelf inventory for SPA shops, International Journal of Information Systems for Logistics and Management 4(1): 19-29. 
Haksever, C.; Moussourakis, J. 2005. A model for optimizing multi-product inventory systems with multiple constraints, International Journal of Production Economics 97(1): 18-30. http://dx.doi.org/10.1016/j.ijpe.2004.05.004

Hart, C.; Rafiq, M. 2006. The dimensions of assortment: a proposed hierarchy of assortment decision making, International Review of Retail, Distribution and Consumer Research 16(3): 333-351. http://dx.doi.org/10.1080/09593960600697063

Hassanzadeh, F.; Modarres, M.; Nemati, H. R. 2014. A robust R\&D project portfolio optimization model for pharmaceutical contract research organizations, International Journal of Production Economics 158(1): 18-27. http://dx.doi.org/10.1016/j.ijpe.2014.07.001

Inman, J. J.; Venkatesh, S.; Ferraro, R. 2004. The roles of channel-category associations and geodemographics in channel patronage, Journal of Marketing 68(2): 51-71.

http://dx.doi.org/10.1509/jmkg.68.2.51.27789

Jacobs, M. A. 2013. Compexity: towards an empirical measure, Technovation 33: 111-118.

http://dx.doi.org/10.1016/j.technovation.2013.01.001

Jacobs, M. A.; Swink, M. 2011. Product portfolio architectural complexity and operational performance: incorporating the roles of learning and fixed assets, Journal of Operations Management 29(7): 677-691. http://dx.doi.org/10.1016/j.jom.2011.03.002

Johnson, M.; Selnes, F. 2004. Toward a dynamic theory of exchange relationships: customer portfolio management, Journal of Marketing 68(2): 1-17. http://dx.doi.org/10.1509/jmkg.68.2.1.27786

Jugend, D.; da Silva, S. L. 2014. Product portfolio management: a framework based on Methods, Organization, and Strategy, Concurrent Engineering Research and Applications 22(1): 17-18. http://dx.doi.org/10.1509/jmkg.68.2.1.27786

Kahn, B. E. 1999. Introduction to the special issue: assortment planning, Journal of Retailing 75(3): 289-293. http://dx.doi.org/10.1016/S0022-4359(99)00009-3

Kök, A. G.; Fisher, M. L.; Vaidyanathan, R. 2009. Assortment planning: review of literature and industry practice, Chapter 6 in N. Agrawal, S. A. Smith (Eds.). Retail supply chain management. International series in operations research \& management science, Boston: Springer US, 99-154.

Kumar, B.; Banga, G. 2007. Merchandise planning: an indispensable component of retailing, The Icfaian Journal of Management Research 6(11): 7-19.

Lau, H.-S.; Lau, A. H.-L. 1996. The newsstand problem: a capacitated multiple-product singleperiod inventory problem, European Journal of Operational Research 94(1): 29-42.

http://dx.doi.org/10.1016/0377-2217(95)00192-1

Lee, H. L.; Padmanabhan, V.; Whang, S. 1997. The bullwhip effect in supply chains, Sloan Management Review 38(3): 93-102.

Levy, M.; Weitz, B. A. 1998. Retailing management. 3rd ed. Boston: McGraw-Hill.

Loch, C. H.; Kavadias, S. 2002. Dynamic portfolio selection of NPD programs using marginal returns, Management Science 48(10): 1227-1241. http://dx.doi.org/10.1287/mnsc.48.10.1227.275

Ma, Y.; Ailawadi, K. L.; Gauri, D. K.; Grewal, D. 2011. An empirical investigation of the impact of gasoline prices on grocery shopping behaviour, Journal of Marketing 75(March 2011): 18-35. http://dx.doi.org/10.1509/jmkg.75.2.18

Mallin, M. L.; Finkle, T. A. 2011. Apple Inc.: product portfolio analysis, Journal of International Academy for Case Studies 17(7): 63-74.

Mantrala, M. K.; Levy, M.; Kahn, B. E.; Fox, E. J.; Gaidarev, P.; Dankworth, B.; Shah, D. 2009. Why is assortment planning so difficult for retailers? A framework and research agenda, Journal of Retailing 85(1): 71-83. http://dx.doi.org/10.1016/j.jretai.2008.11.006

Markowitz, H. M. 1959. Portfolio selection. Cowles foundation monograph 16. New York: Willey. 
McNally, R. C.; Durmusoglu, S. S.; Calantone, R. J.; Harmancioglu, N. 2009. Exploring new product portfolio management decisions: the role of managers' dispositional traits, Industrial Marketing Management 38(1): 127-143. http://dx.doi.org/10.1016/j.indmarman.2007.09.006

Mehta, N. 2007. Investigating consumers' purchase incidence and brand choice decisions across multiple product categories: a theoretical and empirical analysis, Marketing Science 26(2): 196-217. http://dx.doi.org/10.1287/mksc.1060.0214

Meyvis, T.; Janiszewski, C. 2004. When are broad brands stronger brands? An accessibility perspective on the formation of brand equity, Journal of Consumer Research 31(2): 346-357 https://doi.org/10.1086/422113

Rajaram, K. 2001. Assortment planning in fashion retailing: methodology, application and analysis, European Journal of Operational Research 129(1): 186-208.

http://dx.doi.org/10.1016/S0377-2217(99)00406-3

Rosenbloom, B. 1980. Strategic planning in retailing: prospects and problems, Journal of Retailing 56(1): 107-120.

Sharpe, W. F. 1970. Portfolio theory and capital markets. New York: McGraw-Hill.

Shin, H.; Park, S.; Lee, E.; Benton, W. C. 2015. Invited review: a classification of the literature on the planning of substitutable products, European Journal of Operational Research 246(3): 686-699. http://dx.doi.org/10.1016/j.ejor.2015.04.013

Sloot, L. M.; Fok, D.; Verhoef, P. C. 2006. The short and long-term impact of an assortment reduction on category sales, Journal of Marketing Research 43(4): 536-548.

http://dx.doi.org/10.1509/jmkr.43.4.536

Swaminathan, J. M.; Tayur, S. R. 1998. Managing broader product lines through delayed differentiation using vanilla boxes, Management Science 44(12): S161-S172.

http://dx.doi.org/10.1287/mnsc.44.12.S161

Ton, Z.; Raman, A. 2010. The effect of product variety and inventory levels on retail store sales: a longitudinal study, Production and Operations Management 19(5): 546-560.

http://dx.doi.org/10.1111/j.1937-5956.2010.01120.x

Trappey, C. V.; Trappey, A. J.; Feinberg, R. 1993. Planning product assortment using portfolio optimization, in G. Fandel, T. Gulledge, A. Jones (Eds.). Operations research in production planning and control. Berlin: Springer-Verlag: 3-20. http://dx.doi.org/10.1007/978-3-642-78063-9_1

Vaagen, H.; Wallace, S. W. 2008. Product variety arising from hedging in the fashion supply chains, International Journal of Production Economics 114(2): 431-455.

http://dx.doi.org/10.1016/j.ijpe.2007.11.013

Van Mieghem, J. A. 2003. Capacity management, investment, and hedging: review and recent developments, Manufacturing and Service Operations Management 5: 269-301.

http://dx.doi.org/10.1287/msom.5.4.269.24882

Wan, X.; Dresner, M. F.; Evers, P. T. 2014. Assessing the dimensions of product variety on performance: the value of product line and pack size, Journal of Business Logistics 35(3): 213-224. http://dx.doi.org/10.1111/jbl.12054 


\section{APPENDIX}

Proof of propositions (3-5). We formulate expected portfolio sales without any assortment changes as:

$$
E\left(y_{p t l}\right)=\sum_{i} y_{i}+t \sum_{i} b_{i}+\sum_{i} c_{i l} .
$$

We denote our random variables and parameter estimators appropriately as $\tilde{y}_{p}, \tilde{y}_{i}, \tilde{b}_{i}, \tilde{c}_{l i}$. Hence, variance of sales is:

$$
\begin{aligned}
& E\left(\tilde{y}_{p}-y_{p}\right)^{2}=E\left[\left(\sum_{i} \tilde{y}_{i}+t \sum_{i} \tilde{b}+\sum_{i} \tilde{c}_{i l}\right)-\left(\sum_{i} y_{i}+t \sum_{i} b_{i}+\sum_{i} c_{i l}\right)\right]^{2}= \\
& E\left[\sum_{i} \tilde{y}_{i}-\sum_{i} y_{i}+t\left(\sum_{i} \tilde{b}-\sum_{i} b_{i}\right)+\sum_{i} \tilde{c}_{i l}-\sum_{i} c_{i l}\right]^{2} .
\end{aligned}
$$

Assuming the independence of residual, seasonal and structural sales effects, we have:

$$
\begin{aligned}
& E\left(\sum_{i}\left(\tilde{y}_{i}-y_{i}\right)\right)^{2}+t^{2} E\left(\sum_{i}\left(\tilde{b}_{i}-b_{i}\right)\right)^{2}+E\left(\sum_{i}\left(\tilde{c}_{i l}-c_{i l}\right)\right)^{2}=\sum_{i} s_{i}^{2}+ \\
& 2 \sum_{i=1}^{I} \sum_{j=i+1}^{I} p_{i j} s_{i} s_{j}+t^{2}\left(\sum_{i} d_{i}^{2}+2 \sum_{i=1}^{I} \sum_{j=i+1}^{I} \rho_{i j}^{b} d_{i} d_{j}\right)+\frac{1}{L} \sum_{l=1}^{L}\left(\sum_{i} c_{i l}-\frac{\sum_{l} \sum_{i} c_{i l}}{L}\right)^{2} .
\end{aligned}
$$

Seasonality generates volatility rather than risk. We calculate seasonal volatility in the last bracket, where the subtrahend equals zero if all effects are additive. Hence, seasonal volatility is:

$$
\frac{1}{L} \sum_{l=1}^{L}\left(\sum_{i} c_{i l}\right)^{2}=\frac{1}{L} \sum_{l=1}^{L} \sum_{i=1}^{I} \sum_{j=1}^{I} c_{i l} c_{j l} .
$$

Hence, the impact of category $k$ reduction on seasonal sales volatility as in (5) is:

$$
-\left(\sum_{l=1}^{L} c_{k l}^{2}+2 \sum_{i \neq k}^{I} \sum_{l=1}^{L} c_{i l} c_{k l}\right) / L
$$

We assumed that coefficient $b$ estimators are perfectly positively correlated, so the impact of category $k$ reduction on structural sales risk as in (3) is:

$$
-t^{2}\left(d_{k}^{2}+2 \sum_{i \neq k}^{I} d_{i} d_{k}\right) .
$$

Further, the impact of category $k$ reduction on residual, or competitive, sales risk as in (4) is:

$$
-\left(s_{k}^{2}+2 \sum_{i \neq k}^{I} \rho_{i k} s_{i} s_{k}\right) \text {. }
$$

Tomasz BRZĘCZEK. An Assistant Professor of Management Engineering at Poznan University of Technology, Poland. He received his PhD in Economics from the Poznan University of Economics, where he was a PhD student in Operations Research Chair. He has been a member of organizing committees at international conferences. He is the author of 2 textbooks for students and many scientific papers. He focuses in his research at risk and efficiency in operations management, finance and marketing modelling. 